\title{
The Capital Assets Pricing Model \& Arbitrage Pricing Theory: Properties and Applications in Jordan
}

\author{
Ibrahim Alshomaly ${ }^{1} \&$ Ra'ed Masa'deh ${ }^{2}$ \\ ${ }^{1}$ Department of Risk Management and Insurance, Faculty of Management and Finance, The University of Jordan, \\ AqabaBranch, Jordan \\ ${ }^{2}$ Department of Management Information Systems, School of Business, The University of Jordan, Amman, \\ Jordan \\ Correspondence: Ibrahim Alshomaly, Department of Risk Management and Insurance, Faculty of Management \\ and Finance, The University of Jordan, AqabaBranch, Jordan. E-mail: i.alshomaly@ju.edu.jo
}

Received: May 29, 2018 Accepted: September 20, 2018 Online Published: October 29, 2018

doi:10.5539/mas.v12n11p330 URL: https://doi.org/10.5539/mas.v12n11p330

\begin{abstract}
This paper aimed to test the validity of capital asset pricing model (CAPM) and arbitrage pricing theory (APT) in Jordanian stock Market using three different firms of three main sectors, financial, industrial, and service sector for the period Q1 (2000) to Q4 (2016), using published information obtained from Amman stock exchange (ASE), these models were designed to measure the cost of capital using the coefficient of systematic risk factor, that used in the valuation of capital assets. We reviewed the most important similarities and differences between the two models out of sectors analysis. The study showed, first, there are some differences between the two models in term of the amount of systematic risk that can be eliminated by diversification in the three sectors. Second, the application of APT model showed that large percentage of risk can be eliminated by diversification more than CAPM model. Third, the banking sector in Jordan faces more systematic risks than other sectors.
\end{abstract}

Key words: CAPM, valuation, stock markets, arbitrage, Jordan

\section{Introduction}

The Market liquidity of is key factor in assets valuation, any deviations from liquidity will be reflected in mispriced assets. For this reason, the major concern of the asset pricing models is to examine the degree of capital market liquidity, the rational behavior included in any financial or investment decisions should aim to improve the liquidity of any instruments exchanged (Brennan \& Subrahmanyam, 1996; Shannak \& Obeidat, 2012; Obeidat et al., 2013; Masa'deh et al., 2015). Therefore, the capital assets pricing model (CAPM) and arbitrage pricing theory (APT) tried to quantify this rationality by modeling the expected returns on any capital investment asset with its relevant risk factors, where any excess returns over pure interest rate (risk free rate) reflects additional risk exposures. The CAPM (Sharpe, 1964, Nobel prize 1990) assumed that investments risks depend mainly on their sensitivity to market risks which considered of systematic risks while the non-systematic risks (firm's specific risks) can be eliminated by holding a diversified asset portfolio according in accordance to market capitalization (Markowitz, 1952). So, any returns in excess of the pure interest rate for any investment will depend on the beta coefficient, which measured by the covariance between investment and market returns, but the validity of this relation is restricted with the presence of several theoretical assumptions that cannot be exist in real market place; like lending and borrowing at the same rate (risk free rate), for example. the APT model (Ross, 1976) which is similar to CAPM, seems to hold more practical implications than CAPM since it correlates the risk premium of capital assets with multifactor models; these factors in its entirety depend on macroeconomics indicators like GDP growth, inflation, and interest rates (Fama \& French, 1993).

In theory, the marginal utility of money is high in small wealth and it is appropriate to be invested in risk free liquid investments (Layard et al., 2008). Consequently, any additional money over this value can be invested in risky assets at a premium, but at the account of investment liquidity. Thus, the liquidity of assets in any investment portfolio should be of the major concerns of any rational investor; the liquidity is achieved if there is a ready market for any investment asset and no arbitrage opportunity exists (market equilibrium). The CAPM and APT assumed that the investment is overpriced or underpriced if the actual returns deviates from required or expected, this will create an arbitrage opportunity which can be eliminated distinctly by continuous price 
adjustments toward equilibrium price or perfect liquidity (Sharpe, 1964). Therefore, these models help to assess market liquidity by proposing appropriate evaluation models of capital assets (Brennan \& Subrahmanyam, 1996).

In this paper we will examine the two models (CAPM and APT) practically using published information obtained from Jordanian stock Market. Then we will review the most important similarities and differences between the two models.

\section{Research Problem and Hypotheses}

The measuring of the cost of capital or discount rate is a key factor in determination the intrinsic value of capital assets, the accuracy of this rate depends on the model that used to calculate more efficiently. The more the model efficiency to quantify the systematic risk the asset faces, the more the accuracy of discount rate generated to measure the assets value. Consequently, assets liquidity is improved if this rate lead to minimize the gap between the price of an assets and its value, so the assets is fairly priced and no chance to gain from speculation or arbitraging. Therefore, in relation to Jordanian stock market, which model (CAPM or APT) is more efficient in the quantification of the systematic risk in each business sector (using three different firms of three main sectors, financial, industrial, and service sector), and is there major differences between the three sectors in this efficiency.

\section{Theories and Literature of Asset Pricing}

The aim of capital pricing theory is improving the liquidity of capital assets through determination of the appropriate discount rate, this rate is measured by quantifying the systematic risks that the assets faces (Fama $\&$ French, 2004). The two main models used for this purpose are CAPM and APT.

\subsection{Capital Assets Pricing Model (CAPM)}

The CAPM model assumed that excess returns of capital assets are positively correlated with its degree of sensitivity to the market risk premium (Michael et al., 1989).

$$
\begin{gathered}
r i-r f=\beta(R m-r f) \\
\text { Excess returns }=\quad \text { market risk premium }
\end{gathered}
$$

The critical factor in the model is the selection of a proxy for pure risk (rf), which represent the minimum return required for risk free investments, after which more risk incurred will require more returns. Moreover, the market returns (Rm) in CAPM model are restricted by the movements of the market indexes of equity portfolio, and this regarded more serious problem where the returns on other investments are ignored.

\subsubsection{The mathematics of CAPM}

The slope of CAPM (security market line SML) is determined by the tangency point between the capital allocation line CAL and the efficient frontier of market portfolio (Markowitz portfolio that achieve the highest possible return for each value of risk) when the wealth invested in risk free investment approach to zero $(\mathrm{W}=1)$ (Markowitz, 1952).

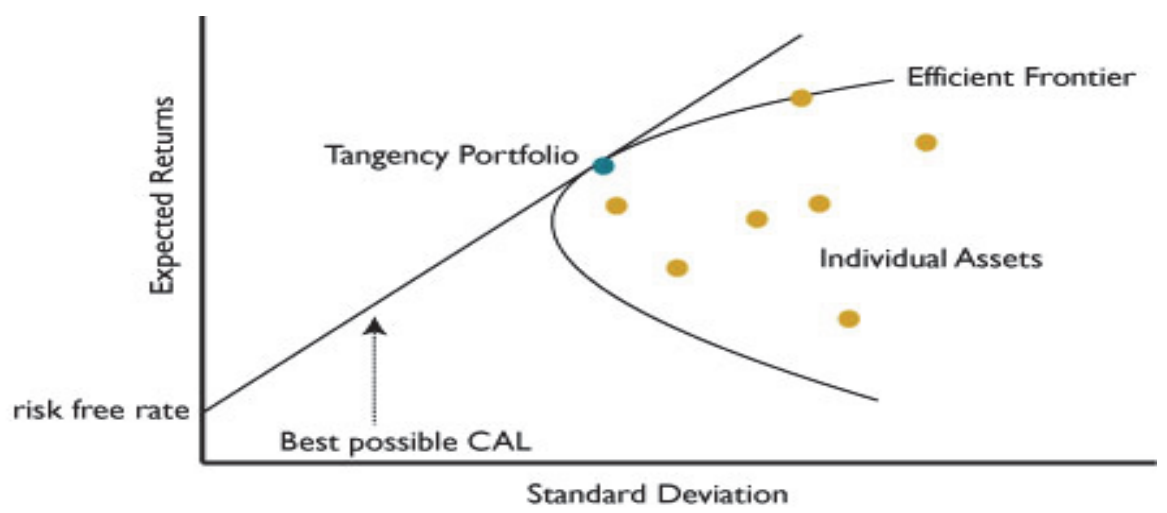

Source: http://www.kotaksecurities.com/mailer/horizon031109/newsletter2.html

The points in the left of tangency portfolio represent lending at risk free rate and invest the remaining wealth in risky market portfolio. While any point to the right represents borrowing at risk free rate to overweight investing 
in risky assets.

A- The capital allocation line CAL

$$
\begin{aligned}
& R p=(1-W) R f+W R m \\
& \sigma p=W \sigma m
\end{aligned}
$$

And therefore:

$$
\begin{gathered}
R p=R f+\frac{\sigma p}{\sigma m}(R m-R f) \\
\frac{d R p}{d \sigma p}=\frac{R m-R f}{\sigma m}
\end{gathered}
$$

B- Efficient frontier (market portfolio)

$$
\begin{gathered}
R p=w r i+(1-w) R m \\
\sigma p=\sqrt[2]{(w \sigma i)^{2}+((1-w) \sigma m)^{2}+2 w(1-w) \sigma i \sigma m \rho i, m} \\
\frac{d R p}{d w}=r i-R M \\
\frac{d \sigma p}{d w}=\frac{\rho i, m-\sigma m^{2}}{\sigma m}
\end{gathered}
$$

Dividing 2 by 3 which equal 1 when $\mathrm{w}=0$

\subsubsection{The assumptions of CAPM}

$$
\begin{aligned}
& r i-r f=\beta(R m-r f) \\
& r i=r f+\beta(R m-r f)
\end{aligned}
$$

The CAPM and its assumptions are the means for estimating the expected return on capital instruments (exclusively represented by the common stocks). The basic assumptions of CAPM include, first, investors are seeking to maximize economic utilities, and they will behave rationally by being risk averse. Second, each individual investor wealth to market capitalization is very low and this implies that they cannot influence prices and take price as given. Third, the model assumes lending and borrowing unlimited amounts at the risk-free rate, and this assumption is vital for adopting arbitraging process that leads to market equilibrium. Fourth, information is available at market at the same time to all investors and this will prevent any investor from make abnormal return since all information are reflected in stock prices. Fifth, the CAPM assume that no taxation or transaction costs, the absence of this assumption means the market liquidity will be affected and prices will behave in volatile trends. Finally, but not all, all investors invest for the same single time period in order to make comparable returns on different securities, that the investment return over three months, for example, cannot be compared with a return over 12 months. Even if these assumptions seem unrealistic and lead for historical criticisms, the CAPM model still important, this importance stems from the implications behind these assumptions (Sharpe, 1964).

\subsubsection{CAPM and Stock Valuation}

The valuation of stocks requires the determination of the cost of capital or the required rate of return on equity capital. The cost of equity capital reflects the degree of risk or uncertainty concerning the future benefits of retention. CAPM provides alternative way which determines the expected or required rate of return on capital whereby the future benefits will be discounted (equity valuation). Efficient application of the valuation models requires an appropriate determination of discount rate. 
In this section we will present some of valuation models:

A- The dividend discount models

1- Dividends with constant growth rate model:

The model assumes that dividends distributions are growing at constant rate for perpetual, the present value of these dividends (ignore the sell price since its PV is approach to zero) using the cost of equity.

$$
\text { value of stock }=\frac{D_{\mathrm{o}}(1+g)}{r-g}
$$

2- Constant dividends model :

The model assumes that dividends are expected to grow at zero rate or dividends are constant:

$$
\text { value of stock }=\frac{D}{r}
$$

Weakness of the dividends models:

1- The two models hold unrealistic by assuming constancy of dividends growth rate or the dividend amounts itself.

2- If the growth rate is more than discount rate then first model will not applicable.

3- Some firms rarely pay dividends and therefore the two models will not be appropriate for valuation.

\section{B- Cash flows valuation model}

The mechanism of this model is similar to the previous models but it uses the discounted future cash flows instead of stock dividends:

$$
\text { value of stock }=\frac{F C F_{\mathrm{o}}(1+g)}{r-g}
$$

Even though the model suffers of the same problem of dividends model that the determination of the cash flows is complex activity and require arbitrary mechanism of determination.

\subsubsection{Summary of the Valuation Models}

The CAPM and APT gives different alternatives for evaluating stocks, but these alternatives may give results may deviate from the true values. The appropriate valuation of equity instrument is a function of its market liquidity where all relevant information about stocks are available and there is an organized mechanism for matching the supply and demand sides for any stock exchanged (market making). The presence of such mechanisms will increase the trade turnover which will improve the trade efficiency by eliminating any arbitrage process and markets will be in equilibrium at fair stock prices. Therefore, for any valuation model should take the liquidity dimensions into account in measuring the required rate of return which is used in common stock valuation.

\subsubsection{Other Practical Uses of CAPM}

Even though the application of CAPM is difficult but the model may be useful in:

1- Determine the required return on risky investments

2- The valuation of assets using CAPM permit to select the appropriate active investment strategy if mispriced assets exists.

3- Reaching capital market equilibrium, where (ri-rf) $=\beta$ (Rm-rf), will enhance the liquidity of the market.

4- Determine the degree of market efficiency by elimination of any arbitrage opportunity using speedy mechanisms.

\subsection{Arbitrage Pricing Model APT}

The arbitrage pricing theory assumptions are more realistic than CAPM, that APT model links the excess returns of stocks in multifactor model (Fama, 1996). The model depends on macroeconomic indicators like interest rate, inflation, GDP growth, and other variables that may have relevant effect on stock returns like market return. Therefore, according to APT, the returns on capital assets is subjected to more risk factors and require more risk premium at varying values according to its sensitivity with each macroeconomic factor. 


\subsubsection{The Assumption of APT}

1- Capital markets are perfectly competitive, so investors cannot influence market prices, same as CAPM,

2- Investors always prefer more wealth to less wealth with certainty, the same as risk adverse assumption in CAPM,

3- The stochastic process generating asset returns can be expressed as a linear function of asset of $\mathrm{N}$ factors or indexes, unlike CAPM which linearly depend on one factor.

3.2.2 Assumptions of CAPM not used APT does not assume

1-A market portfolio that contains all risky assets, and is mean-variance efficient,

2-Normally distributed security returns,

3-Quadratic utility function.

\section{Research Methodology}

Testing of CAPM in actual markets requires the adoption of historical data concerning the periodical stock prices, market indexes, and the risk-free rates. We obtained quarterly data related to three firms listed in Amman stock exchange (ASE) that represent three different sectors, the banking, service, and industrial sector for the period Q1(2000) to Q4(2016).

The analysis process includes calculating beta coefficient which represents the systematic risk factor for each stock in each sector in Jordan using closing prices at the end of each period (Alshomaly, 2014), then use this values of beta will be used to measure:

1- The returns of each firm calculated using the closing stock prices,

2- Subtracting these returns from risk free rate (the rate of lending for one night),

3- Subtracting market return form risk free rate,

4- Run single factor model.

The excess return on assets is modeled by the following equation:

$$
r i-r f=\alpha+\beta(R m-r f)+\varepsilon
$$

\subsection{The Assumptions}

1- The expected value of disturbances $\mathrm{E}(\varepsilon)=0$ (non-systematic risk),

2- The covariance between the market risk premium $(\beta(R m-r f))$ and $\varepsilon$ equal zero, this mean that systematic and nonsystematic risk are independent,

3- The parameter of $\alpha=0$, this mean that the model is valid.

\subsection{The Application of APT model}

We will conduct the multifactor model (APT) for the same firms used in CAPM model by adding the growth of GDP as macroeconomic factor that related with stock returns (Roll \& Ross, 1980).

$$
r i-r f=\alpha+\beta 1(R m-r f)+\beta 2(g d p-r f)+\varepsilon
$$

The assumptions of the model:

1- The expected value of disturbances $\mathrm{E}(\varepsilon)=0$ (non-systematic risk)

2- The covariance between the market risk premium $(\beta(R m-r f))$ and $\beta 2(g d p-r f)$ with $\varepsilon$ equal zero, this mean that systematic and nonsystematic risk are independent.

3- The parameter of $\alpha=0$, this mean that the model is valid.

\section{Results Analysis}

\subsection{CAPM: Single Factor Model}

The application of CAPM on study sample using market risk as the only source for systematic risk is summarized by the following table and analysis 
Table 1. The results of regression (single factor model)

\begin{tabular}{llll}
\hline Statistics & JKWB & JELEC & DARDW \\
\hline A & 0.0169 & 0.0139 & -0.01531 \\
& $(0.27)$ & $(0.48)$ & $(0.36)$ \\
B & $0.8259^{* *}$ & $0.8759^{* *}$ & $0.331863^{*}$ \\
F-test & $34.968^{* *}$ & $24.07^{* *}$ & $4.807304^{*}$ \\
R-squire & 0.3432 & 0.2620 & 0.0553 \\
Variance(ri - rf) & 0.0231 & 0.0337 & 0.0189 \\
Variance ( $\beta(\mathrm{Rm}-\mathrm{rf})$ & 0.0081 & 0.0092 & 001323 \\
Variance $(\varepsilon)$ & 0.0151 & 0.0244 & 0.0176 \\
S.d (ri - rf) & 0.1523 & 0.1836 & 0.1376 \\
S.d $(\beta(\mathrm{Rm}-\mathrm{rf})$ & 0.0905 & 0.0960 & 0.0363 \\
S.d $(\varepsilon)$ & 0.1224 & 0.1565 & 0.1327 \\
\hline
\end{tabular}

Since the value of P-value of $\alpha>0.05$, the model is valid for interpreting the variations of excess return by variations of systematic risk with relatively low R-squire values.

\begin{tabular}{lccc}
\hline Statistics & JKWB & JELEC & DARDW \\
\hline Systematic risk & $09.05 \%$ & $09.60 \%$ & $03.63 \%$ \\
Non- systematic risk & $12.24 \%$ & $15.65 \%$ & $13.37 \%$ \\
Diversification ratio & $64.7 \%$ & $72.66 \%$ & $93.01 \%$ \\
\hline
\end{tabular}

This means that large value of assets risk is diversifiable. This result bears two implications, first, the banking firm volatility to systematic risk is larger than service and industrial firms, this may result from the dominance of banking sector on market index, and therefore, its unsystematic risk is relatively low for this bank. Second, there are risk factors not considered by CAPM model that result in relatively high unsystematic risk. The second implication may be in favor of multifactor model (APT) as we will see later.

\subsection{APT the Multi-Factor Model}

The application of APT on study sample will expand the sources of systematic risk to include GPD growth beside market risk, the result of application is shown in the following table and analysis:

Table 2. The results of multiple regression (multifactor model)

\begin{tabular}{lccc}
\hline \multicolumn{1}{c}{ Statistics } & JKWB & JELEC & DARDW \\
\hline$\alpha$ & 0.0192 & 0.0024 & -0.0205 \\
& $(0.23)$ & $(0.89)$ & $(0.23)$ \\
$\beta 1$ & $0.8194^{* *}$ & $0.90812^{* *}$ & $0.3465^{*}$ \\
$\beta 2$ & 0.1515 & $-0.75155^{* *}$ & -0.3437 \\
& $(0.505)$ & & $(0.15)$ \\
F-test & $17.56^{* *}$ & $17.14^{* *}$ & $3.47^{*}$ \\
R-squire & 0.3376 & 0.3319 & 0.0707 \\
Variance(ri - rf) & $2.32 \%$ & $3.37 \%$ & $1.89 \%$ \\
Variance $(\beta 1(\mathrm{Rm}-\mathrm{rf})$ & $0.81 \%$ & $0.99 \%$ & $0.14 \%$ \\
Variance $(\beta 2(\mathrm{gdp}-\mathrm{rf})$ & $0.01 \%$ & $0.27 \%$ & $0.06 \%$ \\
Variance $(\varepsilon)$ & $1.50 \%$ & $2.11 \%$ & $1.69 \%$ \\
S.d (ri $-\mathrm{rf})$ & $15.23 \%$ & $18.36 \%$ & $13.76 \%$ \\
S.d $(\beta 1(\mathrm{Rm}-\mathrm{rf})$ & $8.98 \%$ & $9.95 \%$ & $3.80 \%$ \\
S.d $(\beta 2(\mathrm{gdp}-\mathrm{rf})$ & $1.04 \%$ & $5.18 \%$ & $2.37 \%$ \\
S.d $(\varepsilon)$ & $12.26 \%$ & $14.54 \%$ & $13.01 \%$ \\
\hline
\end{tabular}

Since the value of P-value of $\alpha>0.05$, the model is valid for interpreting the variations of excess return by variations of systematic risk with relatively low $\mathrm{R}$-squire values. 


\begin{tabular}{lccc}
\hline Statistics & JKWB & JELEC & DARDW \\
\hline Systematic risk & $10.02 \%$ & $15.13 \%$ & $6.17 \%$ \\
Non- systematic risk & $12.26 \%$ & $14.54 \%$ & $13.01 \%$ \\
Diversification ratio & 64.65 & 62.26 & $89.41 \%$ \\
\hline
\end{tabular}

\subsection{Comparison between CAPM and APT}

Under APT the value of unsystematic risk that can be eliminated by diversification is lower than CAPM this because the multifactor model restructures the firm specific risk into more systematic risk as we add more factors to the model.

\begin{tabular}{ccc}
\hline Firm & \multicolumn{2}{c}{ Diversified Risk } \\
\hline & APT & CAPM \\
JKWB & $64.65 \%$ & $64.75 \%$ \\
JELEC & $62.66 \%$ & $72.66 \%$ \\
DARD & $89.42 \%$ & $93.01 \%$ \\
\hline
\end{tabular}

Nonetheless, the unsystematic risk measured by the two models still high which mean that more factors that may be ignored may have strong effect on stock returns more than market index and GDP.

\section{Conclusion}

Determining the appropriate discount rate or the cost of equity is fundamental factor in the valuation process to achieve fair and liquid market for investments. The CAPM assume that the degree stock sensitivity to market returns will be reflected in prices, where any change in market returns will lead to price movement according to beta coefficient. The APT model expands equity valuation by adding more (macroeconomic) factors that directly or indirectly affects stock returns. Therefore, the stock prices bear more risk sources and less non-systematic risk role in measuring the cost of equity. In general, whatever the model used in valuation, the asset's liquidity has the direct influence in the valuation process, and question is to what degree the valuation models consider the liquidity in determination of the required rate of return.

\section{References}

Alshomaly, I. (2014). Bank diversification \& the systematic risk of equity portfolio. European Scientific Journal, 10(16), 171-184. Retrieved from https://papers.ssrn.com/sol3/papers.cfm?abstract_id=2461174

Brennan, M. J., \& Subrahmanyam, A. (1996). Market microstructure and asset pricing: On the compensation for illiquidity in stock returns. Journal of Financial Economics, 41(3), 441-464. Retrieved from https://ideas.repec.org/a/eee/jfinec/v41y1996i3p441-464.html

Fama, E. (1996). Multifactor portfolio efficiency and multifactor asset pricing. Journal of Financial and Quantitative Analysis, 31(4), 441-465. Retrieved from https://papers.ssrn.com/sol3/papers.cfm?abstract_id=2695535

Fama, E., \& French, K. (1993). Common risk factors in the returns on stocks and bonds. Journal of Financial Economics, 33(1), 3-56. https://doi.org/10.1016/0304-405X(93)90023-5

Fama, E., \& French, K. (2004). The capital asset pricing model: Theory and evidence. Journal of Economics Perspective, 18(3), 25-46. https://doi.org/10.1257/0895330042162430.

Layard, R., Nickell, S., \& Mayraz, G. (2008). The marginal utility of income. Journal of Public Economics, 92 (2008), 1846-1857. http://darp.lse.ac.uk/papersdb/Layard_etal_(JPubEcon08).pdf

Markowitz, H. (1952). Portfolio selection. Journal of Finance, 7(1), 77-91. Retrieved from https://www.math.ust.hk/ maykwok/courses/ma362/07F/markowitz_JF.pdf

Masa'deh, R., Tayeh, M., Al-Jarrah, I., \& Tarhini, A. (2015). Accounting vs. market-based measures of firm performance related to information technology investments. International Review of Social Sciences and Humanities, 9(1), 129-145.

Michael, G., Ross, S., \& Shanken, J. (1989). A test of the efficiency of a given portfolio. Econometrica, 57(5), 1121-1152. Retrieved from https://www.jstor.org/stable/pdf/1913625.pdf.

Obeidat, B., El-Rimawi, S., Maqableh, M., \& Al-Jarrah, I. (2013). Evaluating the profitability of the Islamic 
banks in Jordan. European Journal of Economics, Finance and Administrative Sciences, 56, 27-36.

Roll, R., \& Ross, S. (1980). An empirical investigation of the arbitrage pricing theory. Journal of Finance, 35(5), 1073-1103. https://doi.org/10.1111/j.1540-6261.1980.tb02197

Ross, S. (1976). The arbitrage theory of capital asset pricing. Journal of Economic Theory, 13. Retrieved from https://www.top1000funds.com/wp-content/uploads/2014/05

Shannak, R., \& Obeidat, B. (2012). Culture and the implementation process of strategic decisions in Jordan. Journal of Management Research, 4(4), 257-281.

Sharpe, W. F. (1964). Capital asset prices: A theory of market equilibrium under conditions of risk. Journal of Finance, 19(3), 425-442. https://doi.org/10.1111/j.1540-6261.1964.tb02865

\section{Copyrights}

Copyright for this article is retained by the author(s), with first publication rights granted to the journal.

This is an open-access article distributed under the terms and conditions of the Creative Commons Attribution license (http://creativecommons.org/licenses/by/4.0/). 